\title{
Subacute sclerosing panencephalitis: serial electroencephalographic studies
}

\author{
CHRISTIAN HERTEL WULFF \\ From the Laboratory of Clinical Neurophysiology, Rigshospital, University Hospital of Copenhagen, Denmark
}

SUMMARY A total of 42 EEGs from five patients with subacute sclerosing panencephalitis were studied. Periodic complexes were noticed in $35(83 \%)$ of these. The interval between the complexes shortened in all patients with progression of the illness. The gradual EEG changes may reflect the increasing number of infected cells as well as an on-going accumulation of immature virus structures. The records without complexes were either from the early onset (one record) or terminal stage (six records).

Characteristic EEG abnormalities in subacute sclerosing panencephalitis were reported independently in 1949 and $1950 . .^{2}$ They consist of periodic complexes of high voltage occurring very regularly in each individual tracing. High titres of measles antibodies were found in the blood in 1967 as well as evidence of local antibody production in the CNS. ${ }^{3}$ Two years later a measles-like virus was isolated from the brain of a patient with subacute sclerosing panencephalitis. ${ }^{4}$ The study presented in this report deals with changes in the EEG during the course of the disease.

\section{Material and methods}

Forty-two electroencephalograms from five patients with subacute sclerosing panencephalitis were studied. The recordings were done in seven different laboratories. Eight or 16-channel EEG machines were used and the electrode placement followed the International 10-20 system. The recording time was from 20 to 45 minutes. The study comprises all EEGs recorded from these five patients. In one further patient reported from Denmark during the last 10 year period from 1970 to 1979,5 only two records were accessible and this patient was therefore excluded from the study. When possible the time interval between at least 50 complexes were counted.

Measles antibody titres were estimated in the blood in all five patients and in the CSF in four patients. The complement fixation test was used as described by Mordhorst et $a^{6}$ with small modifications. Histological

Address for reprint requests: Dr Christian Hertel Wulff, Laboratory of Clinical Neurophysiology, Rigshospital, Blegdamsvej 9, DK 2100 Copenhagen, Denmark.

Received 15 November 1981

Accepted 18 December 1981 examination of brain material was carried out in three of the cases.

All patients had the typical course of subacute sclerosing panencephalitis starting with personality changes, followed by dementia together with progressive neurological disability including myoclonic jerking, developing into a bedridden and completely helpless state terminated by unconsciousness, decerebration and finally death.

\section{Results}

1 SUBACUTE SCLEROSING PANENCEPHALITIS COMPLEXES

Age, sex and duration of the disease are listed in table 1. There were three boys and two girls, aged from 6 to 12 years. The course of the disease lasted from 4 months to 7 years. EEGs with complexes were recorded from all patients. The number of EEGs studied with subacute sclerosing panencephalitis complexes from each patient was from four to 12 records. The number of EEGs with and without complexes can be seen in table 2. One patient (case 2) had a normal EEG 4 weeks after the onset of the disease, at a time when he had sudden falls. Four weeks later, the EEG contained only a few complexes occurring about every 80 seconds, but 3 weeks later the complexes were well established with a mean interval of 23 seconds. In another patient (case-1) six EEGs were recorded successively where no complexes were present. This was at a time when she became and remained unresponsive. The previous four EEGs all contained classical subacute sclerosing panencephalitis complexes.

The mean interval between the complexes in each EEG was correlated to the time after the onset of the disease (fig 1). The figure shows that there was a 
Table 1 Clinical data of five patients with subacute sclerosing panencephalitis

\begin{tabular}{|c|c|c|c|c|c|c|}
\hline \multirow[t]{2}{*}{ Case } & \multirow[t]{2}{*}{ Age $(y r)$} & \multirow[t]{2}{*}{ Sex } & \multirow[t]{2}{*}{$\begin{array}{l}\text { Duration of } \\
\text { disease }(y r)\end{array}$} & \multirow[t]{2}{*}{$\begin{array}{l}\text { Periodic EEG } \\
\text { complexes }\end{array}$} & \multicolumn{2}{|c|}{$\begin{array}{l}\text { Measles antibody titres, first } \\
\text { examination }\end{array}$} \\
\hline & & & & & Blood & $C S F$ \\
\hline $\begin{array}{l}1 \\
2 \\
3 \\
4 \\
5\end{array}$ & $\begin{array}{r}9 \\
11 \\
9 \\
6 \\
11\end{array}$ & $\begin{array}{l}\mathbf{F} \\
\mathbf{M} \\
\mathbf{F} \\
\mathbf{M} \\
\mathbf{M}\end{array}$ & $\begin{array}{l}7 \\
3 \\
2 \\
3 \\
1\end{array}$ & $\begin{array}{l}+ \\
+ \\
+ \\
+ \\
+\end{array}$ & $\begin{array}{l}2048 \\
4096 \\
4096 \\
2048 \\
2048\end{array}$ & $\begin{array}{l}- \\
64 \\
32 \\
16 \\
32\end{array}$ \\
\hline
\end{tabular}

Table 2 Forty-two EEGs in five patients with subacute sclerosing panencephalitis

\begin{tabular}{lc}
\hline EEGs with complexes & 35 \\
EEGs without complexes & $7^{*}$ \\
\hline
\end{tabular}

- One EEG recorded at onset, six EEGs recorded at the decerebrated state.

clear relationship between the frequency of the complexes and progression of illness as the mean interval shortened with time. Only three records did not contain as many as $\mathbf{5 0}$ complexes; they were all from the beginning of the disease.

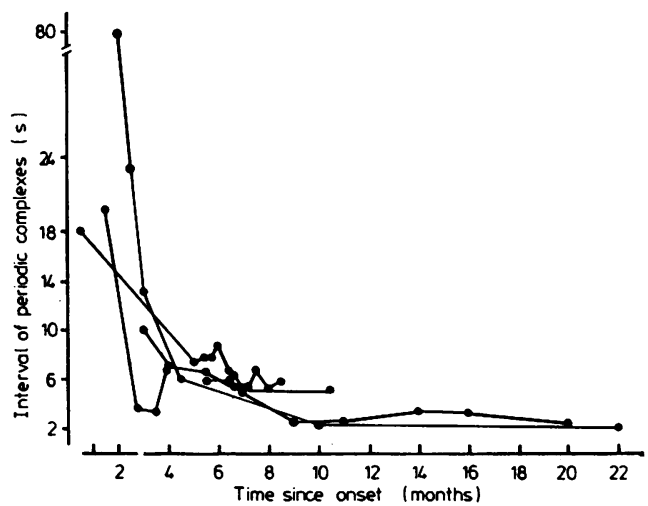

Fig 1 Thirty-five EEGs containing periodic complexes from five children with subacute sclerosing panencephalitis. The interval between the complexes is related to the progression of the illness.

\section{THE BACKGROUND ACTIVITY}

A gradual deterioration of the background activity was noticed. All of the first recordings had a normal background activity except for occasional frontal delta activity. Later the background between the complexes contained more and more abnormal diffuse slow activity, when the patient became severely incapacitated. When the mean interval between the complexes was longer than 7 seconds the background was normal, except for occasional anterior delta activity. When the interval dropped shorter than 5 seconds the background activity was abnormal in all EEGs but one (table 3). Bifrontal or bifronto-temporal $1 \frac{1}{2}-3 \mathrm{~Hz}$ delta rhythms of high voltage were noticed in four records from three patients. The recordings were from the early clinical stages of the disease and the alpha activity over the posterior regions was normal. Follow-up records 5, 10 and 35 days later were without anterior slow activity.

Table 3 Background activity of EEG related to frequency of subacute sclerosing panencephalitis complexes. Thirty-four waking recordings

\begin{tabular}{lll}
\hline Mean interval & $\begin{array}{l}\text { Normal } \\
\text { background }\end{array}$ & $\begin{array}{l}\text { Abnormal } \\
\text { background }\end{array}$ \\
\hline Longer than 7 seconds & $10 *$ & 0 \\
From 7-5 seconds & 8 & 7 \\
Shorter than 5 seconds & 1 & 8 \\
\hline
\end{tabular}

* 4 EEGs contained bifrontal delta activity.

In one patient (case 1) two near-flat EEGs were recorded but the following three EEGs contained theta and delta activity of medium voltage. These recordings were made when she was unresponsive, a stage in which she remained for seven years, until she eventually died. At necropsy hardly any neurons in the cortex or brain stem could be found.

\section{MEASLES ANTIBODIES AND HISTOLOGY} In all patients the titres of the measles antibodies in the blood were substantially raised (table 1). Abnormal high titres of measles antibodies in the CSF were also discovered when looked for. In the case where titres of measles antibodies were not estimated in the CSF there was an abnormal pattern of immunoglobulins consisting of oligoclonal bands. The results of the histological findings are summarised in table 4. As mentioned above extreme atrophy was found in case 1. No inclusion bodies were found in the few remaining neurons and glial cells.

\section{Discussion}

The purpose of this study was to look at a series of 
Table 4 Histological findings in three patients with subacute sclerosing panencephalitis

\begin{tabular}{llll}
\hline & Case I* $^{*}$ & Case 4† & Case 5* \\
\hline Inclusion bodies & - & + & + \\
Perivascular infiltration & + & + & + \\
Neuronal loss & + & $?$ & + \\
Glial changes (astrocytosis) & + & + & + \\
Demyelination & + & + & + \\
Chronic meningeal infiltration & + & - & - \\
\hline
\end{tabular}

*Cases 1 and 5 brain necropsy, tcase 4 brain biopsy.

EEG examinations in patients with subacute sclerosing panencephalitis to see how often the repetitive complexes were present in the recordings, how the time interval between the complexes changed from recording to recording in the same patient, and in which way the background activity changed. In all five patients the first EEG was recorded at the early stage of the disease when personality changes, with or without myoclonic jerking, were dominating. As shown in table 2 there was one case in which the first EEG failed to show the characteristic complexes. However, the first measles antibody titres estimated at the early stage of the disease showed high concentrations in the blood. Once present, periodic complexes were seen in all EEGs throughout the whole recording until the terminal stage. This is in contrast to Cobb's findings: ". . . the complexes ... may disappear for a time during the illness, only to return later". ${ }^{7}$ The disappearance of complexes may be explained by a rise in body temperature due to a febrile illness. ${ }^{8}$ In this material the author is not aware of recordings carried out when the patient was febrile, so this may explain why no such transient EEG changes were observed. Furthermore, the number of patients in this study was small.

The time of onset is difficult to pinpoint in subacute sclerosing panencephalitis but an attempt was made to assess the time of onset in each case. When the mean interval between the complexes from each EEG was plotted against the time of onset ( = time 0 ), an exponential relationship between the frequency of the complexes and the progression in time of the disease was noted, with a shortening of the interval between the complexes as the illness progressed (fig 1). It has previously been said by some authors $^{79-11}$ that no clear relationship between the interval of complexes and progression of disease existed, while others ${ }^{12}$ have found that the interval between the complexes distinctly shortened as the disease progressed. This contradiction may reflect the different opportunities to record from the same patients over long time intervals. As the frequency of complexes and time is exponentially related it is at the beginning of the disease that this relationship is most obvious. Any failure to record from the early onset could further explain why most authors have not been able to demonstrate a frequency/time relationship as shown in this series.

The longest time between the first and last EEG containing complexes in the same patient varied from $2 \frac{1}{2}-20$ months, the longest showing a shortening of the mean interval from 80 seconds to 2 seconds (fig 1). It should be said that in the two patients in whom a mean interval of about 2 seconds were recorded the complexes were very primitive and distorted, hardly resembling a complex (fig 2).

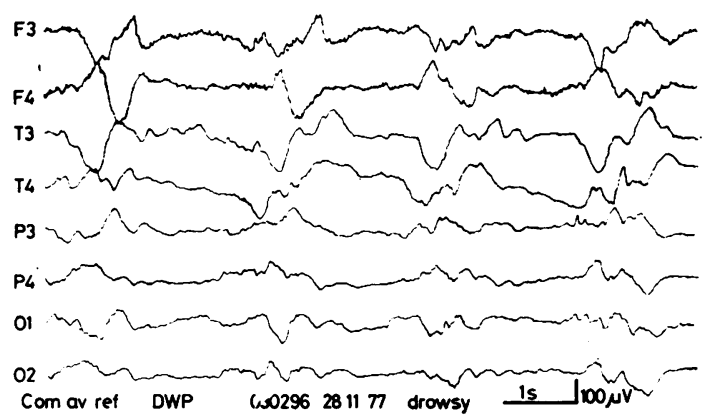

Fig 2 EEG from a boy with subacute sclerosing panencephalitis at the final stage. Note the primitive configuration of the complexes occurring about every $2 \cdot 5 \mathrm{~s}$.

Shortening of the repetition rate of the complexes became obvious not only when the patients were considered as a group, but also in each individual patient. About 6 months after the onset the mean interval dropped to about 6 seconds. The exact mechanism of the periodic events in the EEG is not known. Cobb ${ }^{13}$ suggests that the periodicity represents the time constant of recovery of an electrochemical process at the cellular level. If this is correct it is possible that the shortening of the repetition rate of the complexes reflects a similar shortening of the time constant of recovery. This could be due to the accumulation of virus material in the cell.14 15 As the infection spreads by cell-to-cell fusion, ${ }^{16}$ it is likely that the amount of infected cells increases gradually and exponentially. This may also play a part in the changing EEG pattern reported in this paper.

The gradual change of the background activity from being normal to containing an increasing amount of slow activity is a common accepted finding in subacute sclerosing panencephalitis. 91012 However, frontal delta activity is not a general reported phenomenon in the early stages of the disease. Markand and Panszi ${ }^{12}$ recorded it from half 
of their patients and connected it to disturbance in function of the diencephalic structures. The histological findings were all consistent with subacute sclerosing panencephalitis; inclusion bodies need not be found in all cases, for they can be seen in biopsy material but not in the subsequent brain necropsy, and vice versa. ${ }^{17}$

\section{References}

${ }^{1}$ Radermecker J. Aspects électroencephalographiques dans trois cas d'encéphalite subaiguë. Acta Neurol Belg 1949;49:222-32.

${ }^{2}$ Cobb W, Hill D. Electroencephalogram in subacute progressive encephalitis. Brain 1950;73:392-404.

${ }^{3}$ Connolly JH, Allen Ingrid V, Hurwitz LJ, Millar JHD. Measles-virus antibody and antigen in subacute sclerosing panencephalitis. Lancet 1967;1 :542-4.

${ }^{4}$ Horta-Barbosa L, Fucillo DA, Sever JL, Zeman W. Subacute sclerosing panencephalitis: isolation of measles virus from a brain biopsy. Nature 1969;221: 974.

${ }^{5}$ Mordhorst $\mathrm{CH}$, Wulff $\mathrm{CH}$. Tilfaelde af subakut skleroserende panencefalitis i Danmark 1970-79. Ugeskrift for Lager $1981 ; 143: 3460-3$.

- Mordhorst CH, Tulinius S, Magnus H von. Use of two live measles vaccines in virgin population in arctic Greenland. Dan Med Bull 1968;15:263-70.

' Cobb WA. Pathophysiological basis of abnormalities with various distributions in time. In: Remond A, ed. Handbook of Electroencephalography and Clinical Neurophysiology, Vol 11B. Amsterdam:
Elsevier, 1976:117-30.

${ }^{8}$ Farrell DF, Starr A, Freeman JM. The effect of body temperature on the "periodic complexes" of subacute sclerosing leucoencephalitis (SSLE). Electroencephalogr Clin Neurophysiol 1971;30:415-21.

${ }^{9}$ Cobb W. The periodic events of subacute sclerosing leucoencephalitis. Electroencephalogr Clin Neurophysiol 1966;21:278-94.

${ }^{10}$ Rabending G, Radermecker FJ. Encephalitis due to slow virus infections. Subacute sclerosing panencephalitis. In: Remond A, ed. Handbook of Electroencephalography and Clinical Neurophysiology, Vol 15A. Amsterdam: Elsevier, 1977:28-35.

${ }^{11}$ Ibrahim MM, Jeavons PM. The value of electroencephalography in the diagnosis of subacute sclerosing panencephalitis. Dev Med Child Neurol 1974;16:295-307.

${ }^{12}$ Markand ON, Panszi JG. The electroencephalogram in subacute sclerosing panencephalitis. Arch Neurol $1975 ; 32: 719-26$.

${ }^{13}$ Cobb WA. Evidence on the periodic mechanism in herpes simplex encephalitis. Electroencephalogr Clin Neurophysiol 1979;46:345-50.

14 Choppin PW. Measles virus and chronic neurological diseases. Ann Neurol 1981;9:17-20.

${ }^{15}$ Wechsler SL, Weiner HL, Fields BN. Immune response in subacute sclerosing panencephalitis: Reduced antibody response to the matrix protein of measles virus. J Immunol 1979;123:884-9.

16 Paula-Barbosa MM, Cruz C. Nerve cell fusion in a case of subacute sclerosing panencephalitis. Ann Neurol $1981 ; 9: 400-3$.

${ }^{17}$ Pedersen E, Schiøtt CR. Subacute encephalitis (Dawson). Danish Medical Bulletin 1959;6:241-8. 